\title{
Exploring the Addition of Mobile Access to a Healthcare Services Website
}

\author{
Ruti Gafni \\ Tel Aviv-Yaffo Academic College, \\ and Open University of Israel
}

\author{
rutigafn@mta.ac.il
}

\author{
Ory Barak \\ Open University of Israel
}

obarak@gmail.com

\begin{abstract}
Firms and organizations are aware of the rapid expansion of mobile devices' usage, and therefore decide to develop suitable mobile interfaces in order to allow customers to access their existing websites ubiquitously. This paper explores the adoption of the mobile portal developed for different kinds of mobile phones by a healthcare services company, used by the insured members, who are accustomed to getting the same services by other means, for example, by using the company's stationary internet portal. The research was performed by collecting usage data from both the stationary and mobile portals. The data were collected during one year, starting from the launching of the mobile services. The findings according the collected usage data reveal a constant growth in the awareness and usage of the mobile channel, which tripled during the first year, while the internet usage increased slightly. Moreover, the diurnal usage pattern was found to be different between the stationary and mobile portals, where stationary usage fits the working hours, while the mobile usage is prolonged to the night hours and more homogeneous during the day.
\end{abstract}

Keywords: Mobile Internet, Stationary Internet, Mobile Adoption, Diurnal Usage, Healthcare services.

\section{Introduction}

The evolution of mobile technology, particularly the emergence of smartphones, and the fact that people carry their mobile devices all time wherever they go, led to the use of information through handheld devices anytime and anywhere, and broadened the use of mobile phones from voice calls to services accessed through the mobile web. Many firms and organizations are aware of this tendency, and decide to develop a suitable mobile interface to allow their customers ubiquitous access to their website, which was previously accessed only by stationary internet, meaning through PC computers and mobile computers (laptops). There are several reasons to develop such

Material published as part of this publication, either on-line or in print, is copyrighted by the Informing Science Institute. Permission to make digital or paper copy of part or all of these works for personal or classroom use is granted without fee provided that the copies are not made or distributed for profit or commercial advantage AND that copies 1) bear this notice in full and 2) give the full citation on the first page. It is permissible to abstract these works so long as credit is given. To copy in all other cases or to republish or to post on a server or to redistribute to lists requires specific permission and payment of a fee. Contact Publisher@InformingScience.org to request redistribution permission. an interface, when it is possible to get the same information through other channels. For example, business competition may lead to the necessity to adapt to latest's technologies. Also, inevitable customer demand and business strategy are reasons for developing new communication channels at edge technologies. In the case of the addition of a mobile channel to the stationary web, many firms decided to provide this interface 
before the mass adoption of smartphones, creating the accessibility before demand. The development of mobile interfaces or applications that are used to access existing websites involves reinvestments, additional to those prior performed for the stationary access. These investments are not yet proven as worthy, because the technology is still new, and the consumers are in the first stages of smartphone adoption.

This paper, focusing on healthcare services through mobile internet, is part of a larger study which examines whether the investments in mobile portals by different kinds of organizations are worthwhile. One possibility to foresee the profitability is to check the tendency for adoption and use of these mobile portals, by users accustomed to getting the same information from the stationary website. The rate of adoption of smartphones, and the actual usage of the mobile services (Smith, 2011), can assess the need for such investments. The actual use is not only the amount of users getting information via the mobile channel, but also the usage of such information in different hours or situations, complementing the information received from the stationary internet.

\section{Theoretical Background}

\section{The Usage of Mobile Internet}

Some work has been done to reveal how people use the internet on mobile devices and what is the difference between the use of mobile and stationary web (Chae \& Kim, 2003; Church \& Smyth, 2008; Cui \& Roto, 2008; Kane et al., 2009; Perry, O'Hara, Sellen, Brown, \& Harper, 2001). The major purposes for using mobile internet are reading news, checking mail and information search. Although information seeking is used in both environments, there are differences in the way of usage, based on the devices used to access the web (Halvey, Keane, \& Smyth, 2006a). Using mobile services can provide value such as ubiquity, personalization and flexibility. Moreover, location based services can be offered. Shapiro and Varian (1999) argue that network externalities influence the willingness of using a new technology, and can explain the acceptance of such. In this case the more users join the service network, the more the organization will expand the spectrum of services, offering extra values to each user and so enlarging the potential interested users.

Mobile information systems face barriers originated from the uncomfortable devices because of their size, tiny screens, small keyboards, and connectivity limits (Barnes \& Huff, 2003; Gafni, 2008), which may reduce the degree of implementation success, if not fully addressed by the developers. In order to access the data through a mobile portal in an appropriate manner, the company has to develop a suitable interface, technically adapted to the characteristics of the mobile devices and to the different operating systems of the appropriate smartphones. These interfaces need also to be designed especially to suit the mobile screens, because of their size, their different usage mode, such as touch screens, and their resolution (Parsons, 2007). Hinman, Spasojevic and Isomursa (2008) found that mobile web users access the same contents they are familiar with in the stationary web, but in a difficult and time consuming way. Nylander, Lundquist, and Brännström (2009) found that sometimes users prefer the mobile web although they are near a computer, especially because of convenience (no need to boot the computer, while phone is always ready) or laziness to move to the room in which there is a computer.

\section{Healthcare Mobile Services}

M-health has been defined as the application of emerging mobile communications and network technologies for healthcare aiming to make healthcare systems more efficient and improving existing services for patients, including sending reminders for appointments or treatments, reporting 
results of tests, and collecting data from patients (Whittaker \& Smith, 2008). Organizations providing healthcare services are developing new mobile applications and interfaces in order to leverage their support and availability of information for insured members. These services and applications consist of new portals to the same data available to the users through the stationary internet. Cocosila and Archer (2010) claimed that most studies about mobile information systems acceptance have been limited to healthcare practitioners, like doctors and nurses. They decided to evaluate the users' reasons to accept a mobile information application for health promotion, which fits the patient-centric view of today's healthcare. However, their study was established on short messages service technology (SMS) sent to the participant patients, and was not based on the advanced and more modern mobile services used by browsing the mobile internet or using applications for smartphones.

\section{Diurnal Activity Patterns}

Studies of human activity patterns demonstrate that human behavior in western cultural environments follows a time management pattern, which can be divided into two time resolutions: (1) Day of week patterns, organizing the week in work days and work free weekends; and (2) Diurnal patterns, organizing the day-to day activities base on the diurnal patterns of sleep, work, lunch and leisure (Klepeis et al., 2001). In this work the focus is on diurnal patterns.

Falaki et al. (2010) examined the diurnal patterns of mobile usage in order to estimate the battery energy needs. They found that a strong diurnal pattern exists in the usage of mobile smartphones. Moreover, they found that although the usage at night is low, it is not completely zero. They interpret this fact by a combination of irregular sleeping hours and users using their devices to check the time in the middle of the night.

\section{The Adoption of Mobile Internet}

The mobile portal to the internet data is a voluntary system; users are not obliged to use this system, so the growth of the number of users and visits to the mobile system through time can indicate the value supplied by the system. The adoption of mobile internet can be inspected according to technology acceptance theories, which examine the factors influencing the adoption of new technologies. Barnes and Huff (2003) collected the factors defined by other researchers (Rogers, 2003; Ajzen, 1980; Karahanna, Straub, \& Chervany, 1999, and others), and composed a list of factors that influence the adoption of a mobile phone browser. These factors are relative advantage, compatibility, complexity, trialability, observability, image, trust and intention.

\section{Research Questions}

This research examines whether the development of a mobile channel to obtain information, which is available through stationary internet, is worthwhile. The worthiness is measured by the adoption of this channel by the users.

1. Do the adoption and usage of the mobile channel in healthcare services, when having the possibility to get the same information from the stationary internet, grow over the time?

The number of people owning a smartphone is rising over the time. The smartphone users learn how to use the applications of these phones, and adopt more and more applications (Smith, 2011). Although there are difficulties to use the mobile interface, customers are adopting this channel to get information.

H1: The use of the mobile web in healthcare services is persistently growing, in a greater rate than the use of stationary internet. 
2. Is the diurnal activity of the mobile healthcare services portal different from the stationary one?

It is interesting to examine if the usage of the new mobile channel substitutes the usage of the stationary one, or, because of its ubiquity, it tends to be used at hours when the stationary web is not handy.

$\mathrm{H} 2$ : The mobile web of the healthcare services is accessed at different hours, days or situations, than the stationary one.

\section{Methodology}

This research is based on data collected from an Israeli company that supplies healthcare services; which offers various services to insured members. The clientele of the company counts about 1.2 millions of insured members over 20 years old (CBS, 2012). As far as one and half year prior to the data collection, the insured members could reach information by phone calls, arriving to the offices, or electronically through the internet portal (using PC's computers or laptops). The electronic information comprised of several different kinds of data: (1) general data, such as administrative information, possibility of finding a relevant service or a doctor, according to the working hours or specialty; or (2) personal data, such as results of medical tests and other, which can be reached after subscribing to the system and entering identity data. At the beginning of 2011, the company decided to expand the access to these services and allow mobile users to reach the needed data through the new wireless platforms, smartphones and tablets). Three access portals were developed for different mobile operating systems: users of mobile smartphones based on Android (Google) can download, via the Android market, an appropriate application adapted for this platform; users of iOS (Apple) platforms can download a suitable application through iTunes; and other users, whose mobile devices can support internet access, can browse the data using an adapted WAP interface. First, a few mobile services were developed and offered to the insured members, like (1) checking test results, (2) getting personal data about the insured member, (3) finding a service supplier, specifically or by parameters. Over the time, as adoption of the new media grew, some more services have been developed, such as (4) making an appointment to a specific service supplier, (5) ordering medicines, (6) following-up of pregnancy data, etc.

The data for this research was collected from the log files of an Israeli healthcare services company, during the period of one year, from January 2011 to December 2011. As information systems produce huge data sets of all tasks logs (Geri \& Geri, 2011), data analytics is used to examine the data sets, letting the data derive meaningful trends and findings (Leventhal, 2010), in order to identify patterns and relationships (Bose, 2009). In this research, the objective is to discover, using the entrance logs accumulated in the stationary and the mobile portals, the diurnal pattern differences of usage and the adoption rate of the new mobile portal among the users. It is important to clarify that all visitors using both channels correspond to the same time zone and all of them are subscribed members of the healthcare services company. The number of members was stable during the year.

The variables collected were the entrances to the mobile and stationary internet portals, and number of visitors per hour and month to both portals.

\section{Results}

According to the accumulated factual data, retrieved from the log files, the differences between the usages of both portals and the degree of the mobile interface adoption can be identified. Table 
1 summarizes usage data, by comparing the number of users and visits of the first and last months in the period examined, and calculating the growth of each. As can be seen, very small parts (less than 200K) of the insured members (about 1200K) use any of these channels (CBS, 2012).

Table 1: Differences between stationary and mobile portals' usage

\begin{tabular}{|l|c|c|c|c|c|c|c|c|}
\hline & \multicolumn{3}{|c|}{ First month } & \multicolumn{3}{c|}{ Last month } & \multicolumn{2}{c|}{ Growth } \\
\hline & Stationary & Mobile & $\begin{array}{c}\text { Ratio } \\
\text { Mob./Stat. }\end{array}$ & Stationary & Mobile & $\begin{array}{c}\text { Ratio } \\
\text { Mob./Stat. }\end{array}$ & Stationary & Mobile \\
\hline $\begin{array}{l}\text { Number } \\
\text { of users }\end{array}$ & $176 \mathrm{~K}$ & $5 \mathrm{~K}$ & 0.03 & $181 \mathrm{~K}$ & $14 \mathrm{~K}$ & 0.08 & $\mathbf{1 . 0 3}$ & $\mathbf{2 . 8}$ \\
\hline $\begin{array}{l}\text { Number } \\
\text { of visits }\end{array}$ & $607 \mathrm{~K}$ & $38 \mathrm{~K}$ & 0.06 & $679 \mathrm{~K}$ & $104 \mathrm{~K}$ & 0.15 & $\mathbf{1 . 1 2}$ & $\mathbf{2 . 7 4}$ \\
\hline $\begin{array}{l}\text { Visits } \\
\text { per user }\end{array}$ & 3.8 & 7.6 & 2 & 3.75 & 7.43 & 1.98 & 0.98 & 0.98 \\
\hline
\end{tabular}

Although the number of visits to the mobile website is lower compared to the stationary one, there is a significant growth of users and visits to the mobile portal, which has almost tripled during the year, as seen in Table 1 (Mobile Growth column), while the visits to the stationary has grown very moderated $\left[\chi^{2}(\mathrm{df}=1, N=1,428,000)=21571.67, p<.0001\right]$. The number of visits per month is detailed in Figure 1 (in thousands of visits). (Remark: April and September were months with a concentration of holidays).

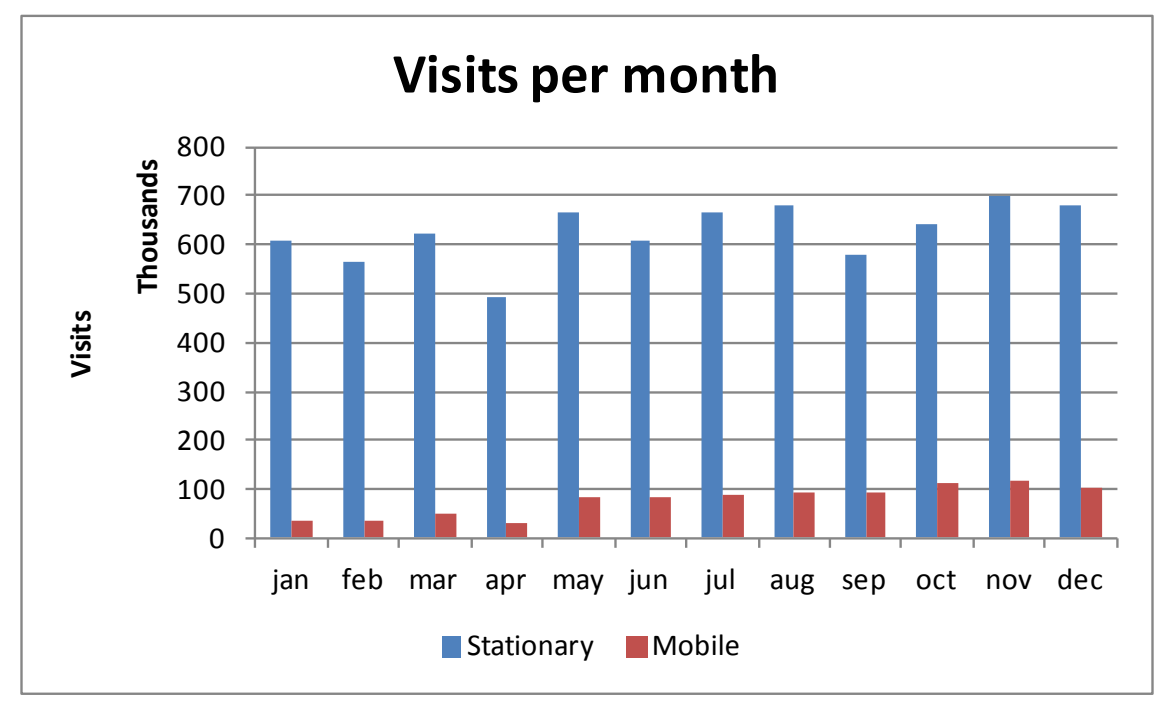

Figure 1: Number of visits per month

The average number of visits per user to the mobile website is double compared to the stationary internet, all year long. The only exception is in April, during the holidays, where the average number of visits per user on the stationary portal slightly reduced, but on the mobile portal grew in about $50 \%$ (Figure 2). Moreover, as seen in Table 1, the number of visits per user, for each channel, was not changed during the year. 


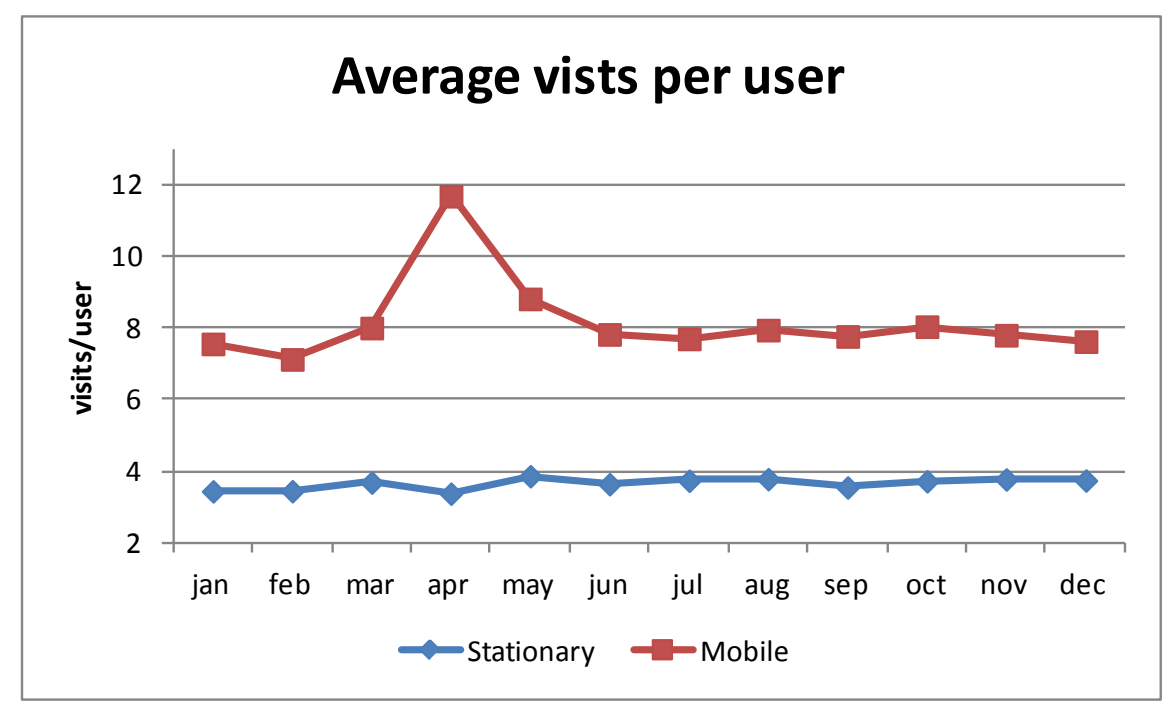

Figure 2: Average visits per user per month

When comparing the number of visits to each platform according to the entrance hour, it can be seen that the diurnal usage pattern of each platform is different. Most of the usage of the stationary website is performed during working hours, 8:00-17:00, starting the usage decline after 14:00, till the late night hours. In contrast to this behavior, the usage of the mobile website is almost the same between 8:00 and 23:00, with a very mild peak at 17:00, as seen in Figure 3.

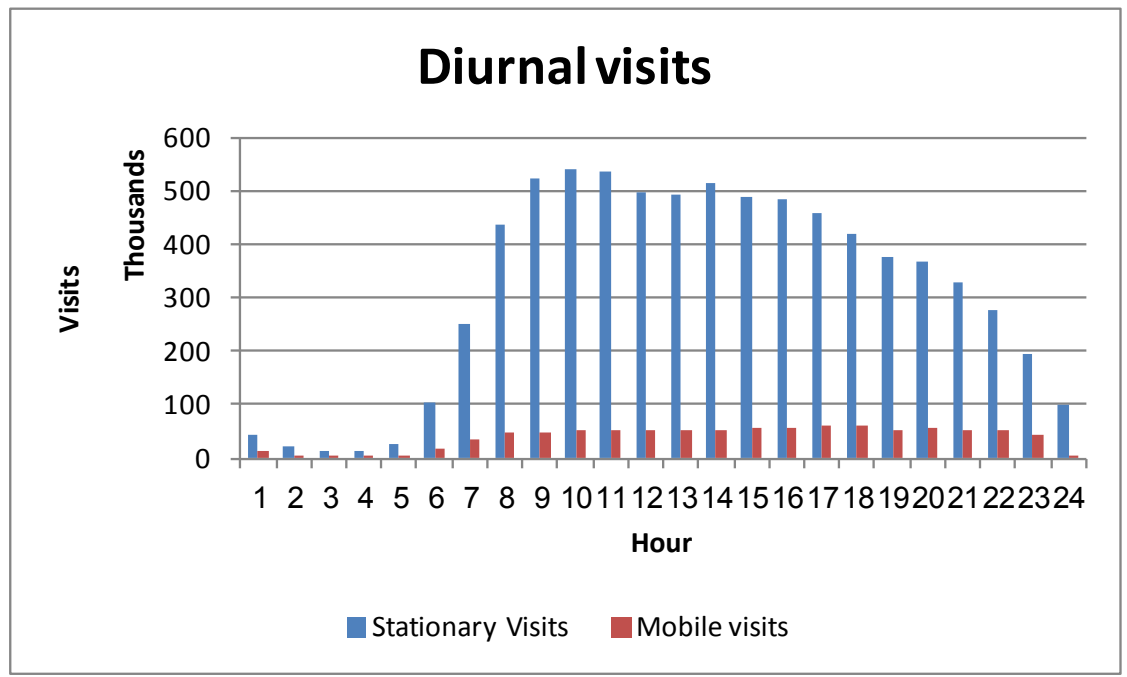

Figure 3: Number of visits per hour

In order to check the differences in time, the percentages of use for each type of portal, were calculated for each hour of the day, i.e., the percentage of visitors for each hour from among the total of visitors in the specific platform. Most of the traffic, in both portals, as seen in Figure 4, occurs from 8:00 to 17:00 which are the regular working hours. However, the percent of mobile usage before and after working hours is greater than the stationary. 


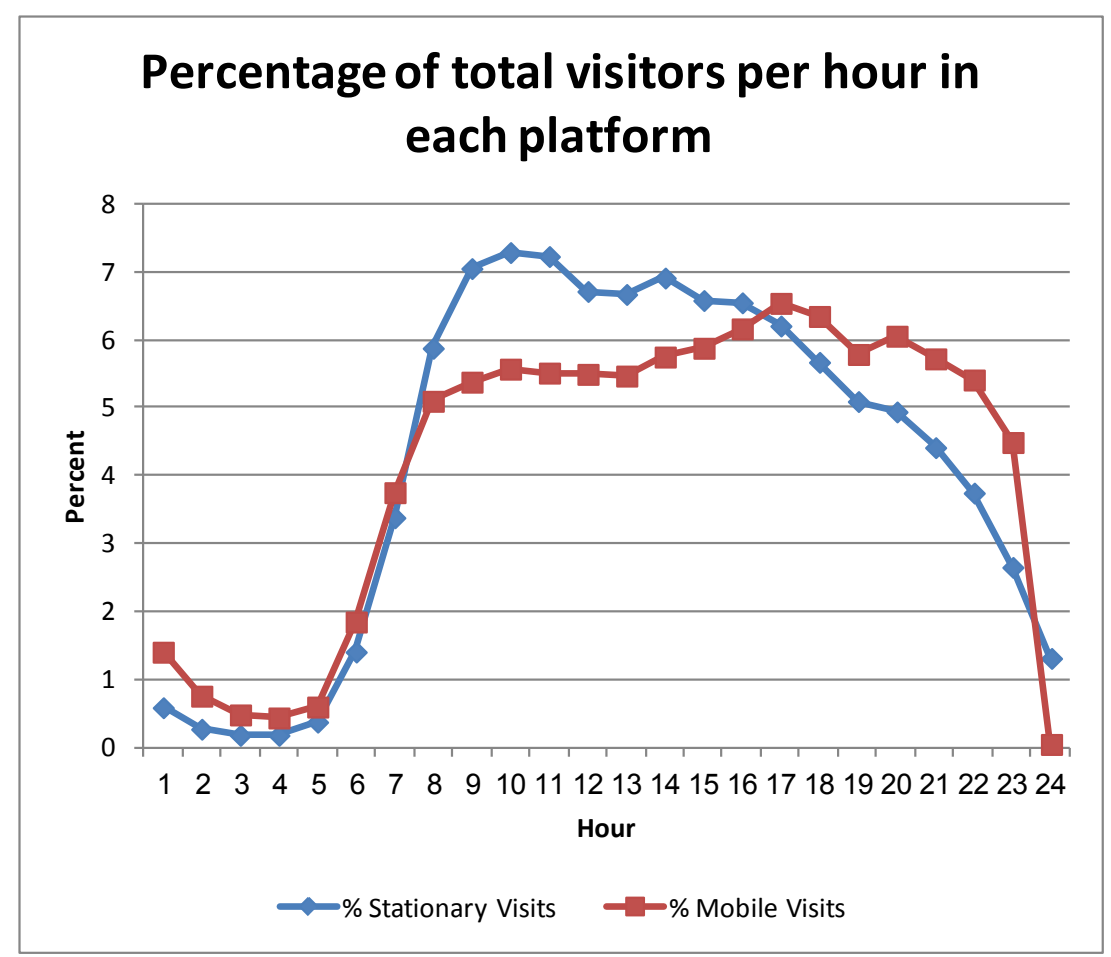

Figure 4: Percentage of Hourly Visits

\section{Discussion}

Despite the fact that both portals contain the same data, the usage patterns of each are different and the emerging mobile interface is growing, as shown in the result section.

The number of users of the stationary internet portal is significantly greater than the number of users of the new mobile portal. This can be explained in two ways. On the one hand, the stationary internet portal exists for some years, and the insured members are accustomed to it, while the mobile portal is new. Second, the number of people having a smartphone, which is a relatively new technology, is small compared to the number of people having a computer with internet access (Smith, 2011), and people are still learning to use their smartphone.

Although there is a large difference in the number of users of both platforms, when looking to the tendency of growth a different picture is shown. The usage of the mobile portal, measured by the number of visits, tripled during the first year; while the usage of the stationary portal grew moderately. In order to get information from the internet portal, the user must reach a computer. This is approachable when being at home or in the office. But, when people hold a smartphone with them during all the time, it is simpler and faster to get the information needed all through the day, wherever they are.

At first, the mobile portal proposed contents that insured members could receive through the stationary portal, but in a ubiquitous manner, according to Hinman et al. (2008). It can be seen that the more users join the service network, the more the company expanded the spectrum of services offered. The first services offered were search of medical services and the option to get test results ubiquitously. When the company felt that the mobile services were accepted by the public and are frequently used, the company decided to add more services, like pregnancy follow up, or the option to get a medical appointment, giving extra value to each user, according to network externalities (Shapiro \& Varian, 1999). 
All the facts mentioned above support the first hypothesis of the research: The usage of the mobile channel is persistently growing, although the users can receive the same information in a known and more traditional manner, like the stationary internet portal.

Moreover, the mobile usage complements the stationary one in some different manners, producing a different pattern of usage.

It is possible to see in Figure 2, that the average visits per user are double when using a mobile device. Moreover, when the user is on vacations or holidays, such as the month of April, the usage of the stationary portal slightly reduces, while the usage of the mobile portal rises by $50 \%$.

The information, both at the stationary and mobile portals, can be attained at any hour of the day, but the users have a very strong diurnal pattern of usage (Figures 3 and 4), which complies with prior research (Karlson, Meyers, Jacobs, Johns \& Kane, 2009). In order to understand the influences of the full day availability of computers and communications infrastructure on the time usage of these resources, Spennemann (2007) examined server traffic statistics in Australian universities, and reported that the usage is almost totally in the working hours, where $72 \%$ accessed the online resources between 08:00-17:00.

When comparing the diurnal usage pattern between both channels, differences can be diagnosed. The stationary internet access is mostly performed during working hours, 9:00-18:00, while the mobile traffic expands through the evening and the early night hours, spreading over the day, from 8:00 till 22:00. This suits the findings in other mobile researches (Halvey, Keane, \& Smyth, 2006b; Beitzel, Jensen, Chowdhury, Grossman, \& Frieder, 2004). Falaki et al. (2010) found that a strong diurnal pattern exists in the usage of mobile smartphones, with a minimal usage at night, which is not completely zero.

Furthermore, when examining the percentage of total visitors per hour in each platform (Figure 4), it can be seen that mobile users tend to seek for information at night, in the early morning and in the early night hours more than the stationary users. In these cases, maybe the users have not access to a stationary computer, or maybe it is more convenient to have a smartphone handy and accessible. Karlson et al. (2009) found that even people, who do not use their phone heavily, still use it every morning and evening.

As shown, the second hypothesis of the research is supported: The mobile internet is accessed in different hours or situations than the stationary one.

The results can also be examined according to the factors that influence the adoption of a new technology in general, using the theory of diffusion of innovations (Rogers, 2003), and specifically using the theory of adoption of mobile technology (Barnes \& Huff, 2003), which can also explain the growth of the mobile internet usage and the differences in the diurnal activities:

Relative advantage - The mobile portal can be reached "anyplace - anytime", wherever the data is needed. This is a relative advantage, for example, for any person troubled about the results of a medical test, which can be seen without the need to wait until they reach a stationary computer.

Compatibility - The mobile portal content is compatible with the stationary one, as for the first services offered by the mobile portal; the same data can be retrieved from both portals. The adoption of this media will give rise simultaneously with the development of new services, especially defined for mobile devices, which cannot be consumed through the stationary portal, like location based services. These services will also increase the relative advantage of the mobile portal.

Complexity - If the user interface is developed in harmony with the device characteristics, the complexity declines (Gafni, 2008). In this case, the healthcare services company developed a suitable application for each kind of device. The use of this channel is handy and intuitive, which 
causes the users to actually visit the website twice as much as the visits through the stationary channel (Table 1 and Figure 2).

Trialability - Each insured member who owns a mobile device can freely try and experience the new mobile portal, and decide whether to use it. The subscription to the site facilitates the use of both internet and mobile channels. The increasing number of visits to the mobile portal (Figure 1) shows the success of the trials.

Observability - Although the data retrieved from mobile phones is not visible to others, and has private characteristics, especially when dealing with personal medical data, people may hear from their family members, or from friends, or even people they meet while waiting for a medical exam, about the mobile service, its ease of use, or problems related with it. However, we have no way to measure it.

Image - People using their mobile phone to retrieve data, especially in public places, feel enhanced prestige and image (Ong, Poong \& Ng, 2008).

Trust - The use of the mobile portal is supported by two suppliers - the wireless network supplier and the content supplier. Both suppliers are known to the subscribers from prior experiences and therefore are trustworthy, otherwise they would have changed them. Grayston, Fairhurst and McKinstry (2010) claimed that patients were not willing to get their test results by SMS or website, because of mistrust on the information security and confidentiality concerns, like the possibility that the results could be seen by others. However, as can be seen in Table 1 and Figure 1, the number of users and visits is continuously growing.

Intention - All the previous factors explain the intention to use mobile. Moreover, the results demonstrate that although this new technology is in the first stages of adoption, the usage is continuously growing presenting the intention of customers to adopt the mobile interface, as can be seen by the number of visits per month (Figure 1). Moreover, according to Table 1 and Figure 2, the average mobile visits per user per month (almost 8 ) are twice the number of visits to the stationary portal (almost 4).

As can be seen, the analysis of most of the factors supports the growth tendency of the mobile channel to the web.

\section{Conclusion}

This research shows that although the information can be retrieved by the users using familiar and known information channels, they sometimes look for new and convenient ways to get to the same data.

The stationary internet portal in the healthcare services company has existed for some years; it has already attained the recognition of its usefulness by the potential users, but nevertheless continues to slowly expand. In contrast, the emerging mobile portal has tripled its popularity during its first year.

One of the reasons of the success of this mobile portal is the fact that it was developed for three different accessing modes in order to fit the various kinds of devices used by the insured members, and to avoid compatibility problems (Gafni, 2008; Parsons, 2007). But principally, the usage of the mobile internet portal is being adopted because of the possibility to get the information ubiquitously, at any time and any place, defining new and different patterns of diurnal usage. 


\section{Limitations and Future Work}

The limitations of this research rely on the fact that the data allowed to be used are partial. The data had to be aggregated and anonymous in order to be received, preventing examination of the population itself. For example, it was impossible to check if same members use both channels at different hours or the number of visits per member.

Hopefully, data about the usage of the different services offered by the healthcare services company will be received, hence giving the possibility to examine the visiting patterns of individual services within the portal.

This research is part of several studies which examine different aspects of the use of mobile devices for browsing websites of firms and organizations, intending to find whether there are benefits in developing special interfaces for users of mobile devices. Further research will compare the usage behavior differences between types of organizations and types of information retrieved by the user.

\section{References}

Ajzen, I. (1980). Understanding attitudes and predicting social behavior. Prentice-Hall, Englewood Cliffs, NJ.

Barnes, S., \& Huff, S. (2003). Rising sun: iMode and the wireless internet. Communications of the ACM, 46(11), 89-96.

Beitzel, S. M., Jensen, E. C., Chowdhury, A., Grossman, D., \& Frieder, O. (2004). Hourly analysis of a very large topically categorized web query log. Proceedings of the 27th Annual ACM Conference on Research and Development in Information Retrieval, 321-328.

Bose, R. (2009). Advanced analytics: Opportunities and challenges. Industrial Management \& Data Systems, 109(2), 155 - 172

CBS. (2012). 2010 social survey on health and way of life: Health insurance. Central Bureau of Statistics, Israel. Retrieved on 24 January 2013 from: http://www.cbs.gov.il/reader/newhodaot/hodaa_template_eng.html?hodaa=201219062

Chae, M., \& Kim, J. (2003). What's so different about the mobile internet? Communications of the ACM, $46(12)$.

Church, K., \& Smyth, B. (2008). Who, what, where \& when: a new approach to mobile search. Proceedings of the 13th International Conference on Intelligent User Interfaces (IUI '08).

Cocosila, M., \& Archer, N. P. (2010). Adoption of mobile ICT for health promotion: An empirical investigation. Electronic Markets, 20, 241-250.

Cui, Y., \& Roto. V. (2008). How people use the web on mobile devices. Proceedings of $W W W^{\prime} 08,905-$ 914.

Falaki, H., Mahajan, R., Kandula, S., Lymberopoulos, D., Govindan, R., \& Estrin, D. (2010). Diversity in smartphone usage. Proceedings International Conference in Mobile Systems, Applications and Services (MobiSys), 2010. ACM Press. 179-194

Gafni, R. (2008). Framework for quality metrics in mobile-wireless information systems. Interdisciplinary Journal of Information, Knowledge, and Management, 3, 23-38. Retrieved from http://www.ijikm.org/Volume3/IJIKMv3p023-038Gafni358.pdf 
Geri, N., \& Geri, Y. (2011). The information age measurement paradox: Collecting too much data. Informing Science Journal, 14, 47 - 59. Retrieved from http://www.inform.nu/Articles/Vol14/ISJv14p047-059Geri587.pdf

Grayston, J., Fairhurst, K., \& McKinstry. (2010). Using new technologies to deliver test results in primary care: structured interview study of patients' views. Primary Health Care Research and Development, 11(2):142-154.

Halvey, M., Keane, M., \& Smyth, B. (2006a). Mobile web surfing is the same as web surfing. Communications of the ACM, 49(3), 76-81.

Halvey, M.; Keane, M., \& Smyth, B. (2006b) Time based patterns in mobile-internet surfing. Proceedings of CHI. 2006, 31-34.

Karahanna, E., Straub, D. W., \& Chervany, N. L. (1999). Information technology adoption across time: A cross-sectional comparison of pre-adoption and post-adoption beliefs. MIS Quarterly, 23(2), 183-213.

Hinman, R.; Spasojevic, M., \& Isomursa, P. (2008). They call it surfing for a reason: Identifying mobile internet needs through pc internet deprivation. In CHI '08: Proceedings of the 26th international conference on Human factors in computing systems, 2195-2208. New York, USA: ACM.

Kane, S. K., Karlson, A. K., Meyers, B. R., Johns, P., Jacobs, A., \& Smith, G. (2009). Exploring crossdevice web use on PCs and mobile devices. Proceedings of Interact, the 12th IFIP TC 13 International Conference on Human-Computer Interaction Uppsala, Sweden, Springer-Verlag. pp. 722-735.

Karlson, A. K.; Meyers, B. R.; Jacobs, A.; Johns, P., \& Kane, S. K. (2009). Working overtime: Patterns of smartphone and PC usage in the day of an information worker. Pervasive Computing, Springer Verlag.

Klepeis, N. E., Nelson, W. C., Ott, W. R., Robinson, J. P., Tsang, A. M., Switzer, P., et al. (2001). The national human activity pattern survey (NHAPS). A resource for assessing exposure to environmental pollutants. Journal of Exposure Analysis and Environmental Epidemiology, 11(3), 231-252

Leventhal, B. (2010). An introduction to data mining and other techniques for advanced analytics. Journal of Direct, Data and Digital Marketing Practice, 12(2), 137-153.

Nylander, S.; Lundquist, T., \& Brännström, A. (2009). At home and with computer access - Why and where people use cell phones to access the internet. Strategies, 2009, 1639-1642.

Ong, J. W., Poong, Y. S., \& Ng, T. H. (2008). 3G services adoption among university students: Diffusion of innovation theory. Communications of the IBIMA, 3(16), 114-121.

Parsons, D. (2007). Mobile portal technologies and business models. In A. Tatnall (Ed.), Encyclopedia of portal technology and applications (pp. 583-586). Hershey, PA: IGI Global.

Perry, M., O'Hara, K., Sellen, A., Brown, B., \& Harper, R., (2001). Dealing with mobility: Understanding access anytime, anywhere. ACM Transactions on Computer-Human Interaction, 8(4), 323-347.

Rogers, E. M. (2003). Diffusion of innovations (5th ed.). New York: The Free Press.

Shapiro, C., \& Varian, H. R. (1999). Information rules. A strategic guide to the network economy. Harvard Business School Press.

Smith, A. (2011). 35\% of American adults own a smartphone. Pew Research Center 2011. Retrieved from http://pewinternet.org/Reports/2011/Smartphones.aspx

Spennemann, D. H. R. (2007). Learning and teaching 24/7: Daily internet usage patterns at nine Australian universities. Campus-Wide Information Systems, 24(1), 27-44. 
Whittaker, R., \& Smith, M. (2008). M-Health - Using mobile phones for healthy behaviour change. International Journal of Mobile Marketing 3(2), 80-85.

\section{Biographies}

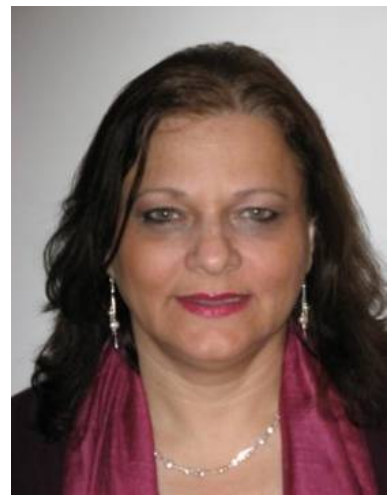

Ruti Gafni is a faculty member in the Management of Information Systems BA program at Tel Aviv-Yaffo Academic College. She holds a PhD from Bar-Ilan University, Israel, in the Business Administration School, focusing on Information Systems. She holds an M.Sc. in Management Sciences from Tel Aviv University and a BA (Cum Laude) in Economics and Computer Science from Bar-Ilan. She has more than 30 years of practical experience as project manager and analyst of information systems. She also teaches in the MBA program of the Management and Economics department at the Open University of Israel.

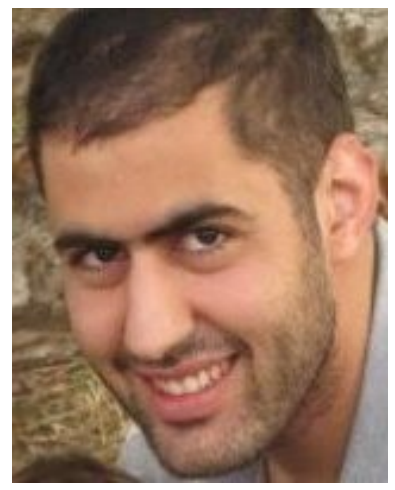

Ory Barak is an experienced IT Systems Engineer who specializes in Microsoft products (Windows Servers, Exchange, SharePoint), Monitoring, Control and Deployment Solutions (HP, CA, Microsoft and more) with strong scripting skills (VBS \& PowerShell). Ory holds a BA in Economics and Management from the Open University of Israel. 